\title{
Medicloud: Hybrid Cloud Computing Framework to Optimize E-Health Activities
}

\author{
Hina Kunwal \\ Department of CS \& IT \\ The University of Lahore \\ Gujrat, Pakistan \\ Dr. Babur Hayat Malik \\ Department of CS \& IT \\ The University of Lahore \\ Gujrat, Pakistan
}

\author{
Amber Saeed \\ Department of CS \& IT \\ The University of Lahore \\ Gujrat, Pakistan \\ Husnain Mushtaq \\ Department of CS \& IT \\ The University of Lahore \\ Gujrat, Pakistan
}

\author{
Hassan Bilal Cheema \\ Department of CS \& IT \\ The University of Lahore \\ Gujrat, Pakistan
Farhat Mehmood
Gujrat, Pakistan \\ Department of CS \& IT \\ The University of Lahore
}

\begin{abstract}
Cloud computing is emerging technology and its usage in health sector is marvelous. It enhances the patient treatment process and allows the physicians to get remotely access to patient medical record anywhere and anytime. Numerous cloud based solution are working currently and offering facilities to people in rural area of developing countries. It is estimated by global healthcare that within few years of adoption of cloud in health sector will increase drastically whereas cloud based health services have opportunities and challenges as well. Privacy, security, interoperability and standards are the factors that influence cloud computing in ehealth. For cloud adoption, organization must understand the existing requirements and make strategy for further development. Cloud offers service and deployment model, each organization select the appropriate model according to their requirements. Interesting thing in cloud is that the responsibility is shared among provider and customer from usage perspective. For initiation of whole procedure service level agreement is signed among customer and provider. Organization can access the cloud services from multiple providers. Hybrid cloud computing is best suitable architecture for health organizations. The whole scenario will provide ease to physician and patient and maximize the work production.
\end{abstract}

Keywords-E-health; cloud computing; hybrid cloud; cloud based services; patient; security; cloud adoption

\section{INTRODUCTION}

Combination of cloud with e-health system is beneficial in numerous ways. In the current scenario diverse sort of electronic systems are working. Traditional health systems make EHR (electronic health record) more expensive and that demand more time for maintenance activities [1], [2]. Due to advancement in technology, it become easy to store and transfer health related data with minimum effort [3], [4]. Similarly, a great amount of data handle with the help of powerful tools. It is duty of the physicians to provide ample treatment according to the condition of patients [5]. To encounter the requirements in the medical industry, a huge number of servers and systems installed for internal communication within the health cloud. Through internet connection that can be delivered to the end users [6].
According to definition of National Institute of Standards and Technology (NIST), Cloud Computing is a model that based upon on request services, convenient features that can be easily accessed via internet from service provider. Characteristics of Cloud computing are: 1) On-demand selfservice: Customer can practice the services according to their own requirements; 2) Broad network access: Access the facilities over the internet; 3) Reserve resources: Utilization of diverse sort of resources; 4) Rapid elasticity: Provider ensure the elasticity in resources as per customer's demand; 5) Measured service: Provider has complete report of resources that utilized by consumer side. There are three cloud service models: 1) Software-as- a-Service (SAAS): Available via web and offer services to end- users for their ease and flexibility; 2) Platform-as-a-Service (PAAS): Act as tool that help the coder and developer to test their software and also help in creation of applications; 3) Infrastructure-as-a-Service (IAAS): On request delivery of services like storage, hardware, etc. [9]

In public clouds, multiple customers share a common infrastructure; in private clouds, cloud services are used by the single organization; in community clouds, several organization accessed the common services; and hybrid clouds are the combination of public, private and community clouds [10] (see Fig. 1).

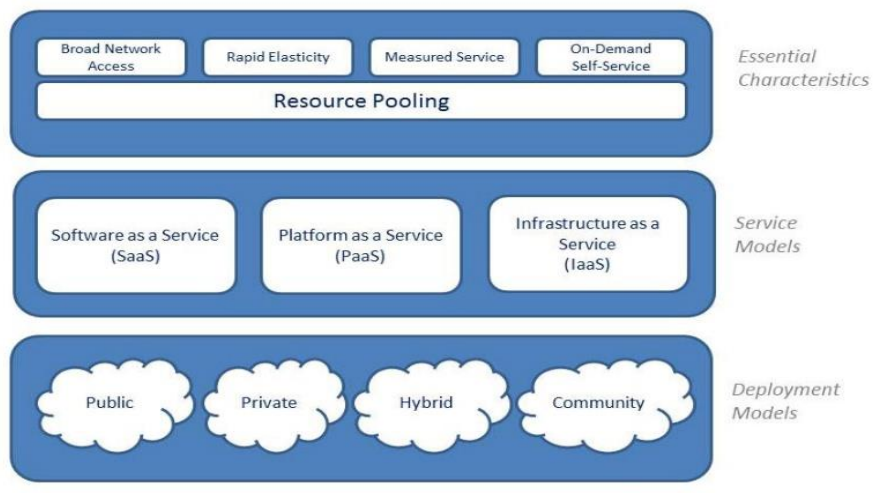

Fig. 1. NIST - Pictorial model of cloud computing. 
Information technology brought revolution in health sector through telemedicine in 1940, but after that one does not notice any technology adaption trend in healthcare. From the last decade, hospitals are spending heavily on IT services [11]. Implementation of IT in healthcare is a tough task then it has caused US to take steps in order to ensure protection of patients' data under HIPAA (Health Insurance Portability and Accountability Act) [29]. Cloud technologies used in healthcare to maintain patient records, to monitor patient progress and to manage diseases efficiently whereas facilitate professionals to communicate with colleagues around the globe [7]. Cloud adoption also provide ability to exchange data between disparate and separate systems. Cloud computing educate healthcare specialists in providing access to medical knowledge and application [8]. Cloud offer key technologies to healthcare like: on demand access, support big data, sharing among authorized specialists and improved the data track ability [11]. In brazil, cloud based platform is used to automatically assemble patient crucial data with the help of sensors from medical systems then shift the data to centralized storage by using cloud where further processing is performed [10].

Until the end of 2021, the growth estimate for the global healthcare will increased due to enriched adoption of healthcare. Major aspects that are responsible for the growing demand for cloud applications is high storage capacity that is why it can be accessed from anywhere and anytime. Also allow clinics and hospitals to store images and provide sharing amid personnel. SaaS is the most widespread form of cloud based service to store health data. Competition among the healthcare cloud market due to large number of vendors across the globe. Vendors are heavily participating in the cloud based solutions to improve their status in the global market [12].

\section{LITERATURE REVIEW}

In health sector, cloud computing emerge as new paradigm and great number of electronic information system shifting to cloud environment. Cloud not just facilitating the hospitals but also act as medical record center. Furthermore, cloud provide ease to organization from infrastructure development and maintenance cost [26]. It has opened new opportunities to access and manage health care data globally. Technologies would be better adopted and maintained. To manage the system in more professional manner that can be done thorough experts and latest procedures [30]. Due to advancement, rural and urban healthcare centers linked together via technology. And that provide relief to doctors for treatment in rural area by using cloud based e-health systems. Cloud implementation assist to achieve the targeted outcome and enrich the patient service level. Moreover enable the management to handle patient data proficiently [31].

Cloud based solution that diagnose and evaluate the patient medical record for better treatment. In UK, London's Chelsea and Westminster Hospital use e-health project as a case. DACAR (known as Data Capture and Auto Identification Reference) tackle common requirements of e-health systems [23]. Effective initiative has been introduced in developing country like Bangladesh, for the development of improved quality of health services. They proposed the usage of SaaS applications that runs on cloud as well as pay per use criteria [22]. In developing countries like Bosnia and Herzegovina, there are numerous issues occur while adoption of e-health services [38]. For the citizens of Uttarakhand, a framework was proposed to properly share patient record locally and at distant location. Cloud service layers are connected with each other through common network point. That concerned service provided to people in the form of software [32]. By deploying cloud based electronic medical record enriches the healthcare facility in rural area of Nigeria [37].

Cloud usage in Indian health sector mainly rely on SaaS sort of cloud. Mainly offers configuration and employment of cloud services in India healthcare and discusses its merits and demerits [43], [44]. Moreover bring gadgets of telemedicine and wireless sensor network inside the cloud environment [45], [46]. Cloud based electronic health record introduced to support health data in rural areas of china. This enable village doctor to manage the chronic disease and discover the environmental harms. Project demonstrate that the practice of cloud computing is worthwhile for both developed and developing countries [25]. In [27], author proposes the CMED (cloud based medical system) that provide healthcare facilities to rural people of developing countries. System generate the output in the form of healthy, alarming and emergency. Moreover patient record save in cloud database by using unique identity for privacy matters. In [40], authors assess the current trend of IT and its associated factors for improvement in the health sector of Iraqi public health sector. They also mentioned the factors like: environmental, structural and personal that effect the utilization of cloud services.

In health sector, they must have electronic record for cloud deployment. A gigantic amount of data gathered and kept on daily bases whereas that imperative for decision making and treatment procedures [36]. Patients manage their health data through patient related electronic record and they have fear about the security of data due to mobility [34]. Physician implement electronic health record due to its flexibility in record sharing. Proposed framework for patient data based upon key-control scheme and that rely on double security. Security mechanism applied upon transmitted and stored data that safe the record from attacker [35].

Security and availability of data is the main concern beside this appropriate selection of cloud provider is also a challenging task. Cloud provider assess on the base of services they offered, that are innovative and cost-effective for patients. In present scenario, usage of cloud offer many opportunities for professionals also there is a need to overcome cloud adoption challenges [24]. Cloud provider must design security plan to grow consumer willingness in this regard. For cloud establishment in Malaysia, the Government requisite to aware health and other ministries to invest heavy amount on it [31].

In Table 1, e-health cloud opportunities and challenges are mentioned [28]. 
TABLE I. OPPORTUNITIES AND CHALLENGES DESCRIPTION

\begin{tabular}{|l|l|l|l|}
\hline Opportunities & Description & Challenges & Description \\
\hline $\begin{array}{l}\text { 1.Improved } \\
\text { patient care }\end{array}$ & $\begin{array}{l}\text { Record } \\
\text { availability }\end{array}$ & 1.Security policy & $\begin{array}{l}\text { Appropriate } \\
\text { authentication } \\
\text { mechanism }\end{array}$ \\
\hline 2.Cost reduction & $\begin{array}{l}\text { Payment of } \\
\text { actual resource } \\
\text { usage. }\end{array}$ & 2.Preservation & $\begin{array}{l}\text { Proper system } \\
\text { maintenance }\end{array}$ \\
\hline $\begin{array}{l}\text { 3.Solve lack of } \\
\text { resource issue }\end{array}$ & $\begin{array}{l}\text { Service } \\
\text { availability at } \\
\text { remote location }\end{array}$ & $\begin{array}{l}\text { 3.Privacy } \\
\text { concerns }\end{array}$ & Loss of data \\
\hline $\begin{array}{l}\text { 4.Finance } \\
\text { provisioning }\end{array}$ & $\begin{array}{l}\text { Act as broker } \\
\text { among } \\
\text { provider and } \\
\text { payer. }\end{array}$ & $\begin{array}{l}\text { 4.Usability } \\
\text { experience }\end{array}$ & $\begin{array}{l}\text { Proper training } \\
\text { for usage }\end{array}$ \\
\hline
\end{tabular}

Cloud adoption in health sector improves service quality and operation efficiency. It also provides better technical support to staff and also offer reduction in cost. Despite of numerous opportunities of cloud, still the pace of cloud adoption in health sector is slow. Three major constraints in adoption of cloud are: technical, organizational and quality challenges. For better cloud based e-health systems, there is need to cater all the concerns of concerning parties [33]. The central problem is linked with the development of e-health applications. That include the absence of strategy, lack of financial resources and shortage of experts [39]. Moreover political, economic and technological challenges are the barriers in the way of development. These challenges overcome through enhanced managerial regulations and quality education [38].

Electronic healthcare documentation (EHD) supports in collection of previous data and help in service execution. A new system of health services was built by using EPR (Electronic Patient Record) which helps to provide custommade services whereas preserve the state-of-the-art medical standards that ensure productive outcome [41]. Authors described the usage of cloud infrastructure as a storage resource. It also states about how the health care systems will be benefited in terms of cost [42].

For security and privacy, healthcare data require protection Liu et al. utilized an identity based encryption (IBE) to control over PHR, or this identity-based cryptography regulation may decrease the complexity concerning answer management [48]. The most preferable encryption technique is Attribute based Encryption (ABE). Three researches [49]-[51] blended ABE and IBE to handle complex situation. Role based access rule is primarily based over $\mathrm{ABE}$, which is an automatic method because authenticating healthcare person data or allocating same role according to guarantee entire associated operations. Tong et al. [52] introduced a Cloud-based Privacy-aware Role Based Access Control model for controllability, traceability about statistics or authorized access according to healthcare resources. Sharma et al. [53] developed an advanced role-based intention known as undertaking based totally power to determine whether or not get entry to ought to stay granted according to a healthcare cloud. toughness Besides get admission to control, various protection safety techniques (Trusted Virtual domains [54], Watermarking method [55], Secure index implementation [56] yet secret-sharing schemes
[57]) had been additionally added to keep the high security and privacy of healthcare clouds.

In [47], author provided a layout for a secure cloud primarily based EHR system using CP-ABE that offers powerful solutions to a number of the problems associated to conventional encryption mechanisms. It additionally investigated the feasibility of adopting $\mathrm{CP}-\mathrm{ABE}$ in terms of overall performance and storage overhead. The outcomes recommend that the proposed layout could offer reasonable performance and utilize negligible storage, and therefore it may be used as an alternative to standard encryption mechanisms in cloud-based totally EHR structures. To secure safe handling of patient's data both the CSP and Healthcare organization should take extreme measures for maintaining security and privacy of healthcare data. To ensure that cloud service providers should comply with the legislation and apply all necessary means to protect patients' data security and privacy Governments' rules and regulations should be in place [36].

\section{CONCEPTUAL FRAMEWORK}

\section{A. Prospects of Cloud Computing in Health Care}

Health industry is having substantial impact on HIT systems. Drastic increase is in demand of health services due to spread of chronic diseases in elder people. Expensive resources create hindrance in the way of quality work. Staff and patients are compelling to adapt the latest technology and providers work to deliver better results through continuous evolution. Cloud based services offer more opportunities as compared to in-house systems. It provides cost-effective, operative and functional merits.

Resources are acquired on demand and pay per use, also minimizing the staff personnel that maintain and deploy the IT systems. Cloud provide better security mechanism for health related data. Provider secure the data from inside and outside threats and protect them through encryption method. From functional perspective, it enhanced the integration within the cloud based healthcare IT systems. Whereas internet based applications that communicate through standard protocols that make the whole communication worthwhile. In the state of the art technological era cloud also encourage the rapid and evolutionary development and satisfy the emerging demands. Exclusive characteristic of health care cloud that they offer wide range of services [13].

\section{B. Factors that Influence Cloud Computing in e-health}

\section{1) Privacy and security}

Strong cloud agreement signed for proper security of data. Where and how data is store and maintained. Additional security measure should be properly addressed and diverse sort of authentication mechanism use for access to cloud. Transfer of data is done through the requirements of security.

\section{2) Regulation and compliance}

Proper implementation of operative measures reside on healthcare entity. All the contractual requirements adhere to the government regulations [14], [15]. Cloud service provider must have certificate that assure the customer about the services legality. And they must have knowledge about country-specific rules and regulations. 


\section{3) Service reliability}

On daily basis, performance must be checked and monitored. Whereas suitable disaster recovery plans ensure the retrieval of data without any loss. Upgradation of system and software must be done on time.

4) Integration, interoperability and portability

Fully integrate the existing system for end to end delivery of information. Among different cloud providers, standard models and interfaces help in migration.

\section{5) Standards}

In health care, varied form of standards are implemented in different aspects. It is better for the customer to have understanding of the existing standards.

\section{High Value Cloud Computing Services for Healthcare}

Healthcare services and their explanation are mentioned in Table 2.

TABLE II. HEALTHCARE SERVICES FOR CLOUd COMPUTING

\begin{tabular}{|l|l|}
\hline Services & Description \\
\hline Population health management & $\begin{array}{l}\text { Track the disease and perform mapping. } \\
\text { Inform the population about the presence } \\
\text { of risk }\end{array}$ \\
\hline Care management support & Cost-effective implementation \\
\hline Image handling services & Offer service to scale up storage system \\
\hline Medical Practitioner assistance & $\begin{array}{l}\text { Practitioner access large amount of data } \\
\text { to produced more treatment plans. }\end{array}$ \\
\hline Patient connectivity & Patient join the health facilities \\
\hline Data distribution services & $\begin{array}{l}\text { Sharing of health related data among } \\
\text { organizations }\end{array}$ \\
\hline Laboratory services & Provide provision to clinical laboratories \\
\hline Clinical research & Exploration of data for in detail research \\
\hline $\begin{array}{l}\text { Intelligent Business Process } \\
\text { Management and Case } \\
\text { Management Low/No-Code } \\
\text { Services }\end{array}$ & $\begin{array}{l}\text { Outsourcing of corporate processes from } \\
\text { cloud }\end{array}$ \\
\hline Diagnostic support & Develop new software services \\
\hline
\end{tabular}

\section{Direction for Cloud Computing in e-health}

For the successful implementation of cloud based e-health system, cloud customers should be focused on the underlying points (see Fig. 2).

\section{1) Construct business case for cloud computing}

Healthcare providers are accepting the emerging importance of cloud computing in health sector. Financial benefit in cloud computing move form capital expense to operational expense. Due to the digitalization and SaaS support a lot of entry barriers disappeared. According to the business goals choose the best service and deployment model. Security is the main concern in cloud computing and providers should offer the certified services.

First of all access the business needs, examine which application must be migrated to cloud, and decide the replacement of cloud services where new abilities are required.

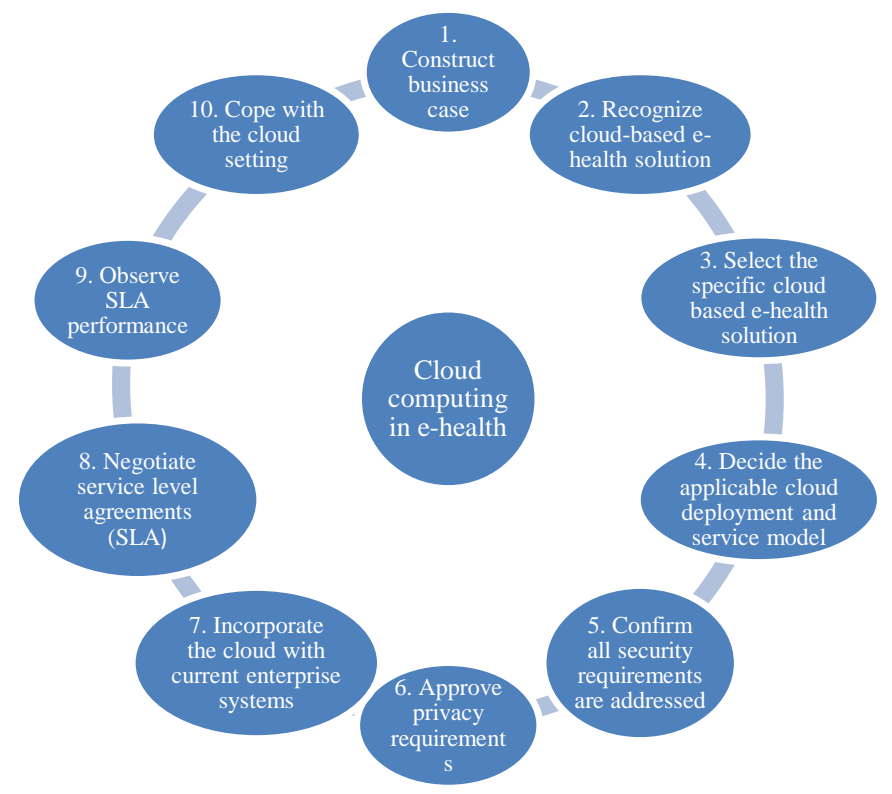

Fig. 2. Cloud computing in e-health.

2) Recognize cloud-based e-health solution

To get the full fledge shift to cloud computing, health organizations should develop the plan to meet its business goals. Beside this keep in mind the existing resources and technology. Identify the cloud that have compatibility with all systems, understanding the need related to cloud, decide the appropriate service provider also make plan for the successful execution.

3) Select the specific cloud based on e-health solution

- Understanding what to move to cloud

- Define your upcoming state

- Avoid platform preference

- Selection of appropriate cloud service provider

- Plan a phased approach

- Establish a test bed

- Manage the production of new applications

4) Decide the applicable cloud deployment and service model

Appropriate selection of deployment and service model is necessary. When decide to move workload on cloud, health organization must consider the number of factors to determine the suitable model. When resources shared among various customer and data resource reside on cloud service provider that called public deployment model. Whereas in private cloud deployment resources accessed by the single entity and controlled by the customer itself. Amalgamation of diverse sort of deployment model together that is managed through hybrid deployment. According to workload, mix form of models are used by the health organization. Where the data exchange place, CSPs must adhere to the security polices for sensitivity of information.

- Selection of service model done on the base of existing in-house resource and IT skills.

- Software-as-a-Service (SaaS): Limited IT skills and inhouse services do not exist. 
- Platform-as-a-Service (PaaS): Acquire new health services and extend to satisfy the demands.

- Infrastructure-as-a-Service (IaaS): Compute existing capacity and look for additional storage requirements.

5) Confirm all security requirements are addressed

In adoption of IT based solutions, security and privacy are the most vital constructs. Here the leading difference between traditional and cloud based solution are the concept of shared responsibility. In cloud scenario, responsibly is shared among customer and provider that based upon the service and deployment model [16]-[19]. Security regulations vary from country to country and they impose obligations that can store and process them.

- Distribute the requirements safeguards in 3 chunks:

- Physical

- Administrative

- Technical

6) Approve privacy requirements

For data confidentiality, encryption is used to make the data unreadable for unauthorized user. Moreover perform the authorization and authentication more complex by using hybrid system. Two factor authentication methods are affordable and frequently used today.

7) Incorporate the cloud with current enterprise systems

Healthcare organizations need skills to tackle on and off premises resources for proper integration of traditional and cloud systems to provide better services to customers.

8) Negotiate service level agreements (SLA)

- Cloud service agreement based upon [20]:

- Clear understanding of business objectives

- Identification of metrics at right time

- Analysis on metrics to perform business decision accurately

It is essential for customer to have proper understanding of cloud services and requirements. Customer should negotiate in detail agreement with provider about all authorized demands. The level of responsibility is shared among provider and customer end.

\section{9) Observe SLA performance}

Cloud strategy of healthcare organizations created in a way that work on immediate quality gains and reduction in cost as well as promoting the new market dynamics. It is difficult to determine the merits further it implement optimization without regular analytics. Make sure the requirements that provider and customer mentioned in agreement is provided or not.

\section{0) Cope with the cloud setting}

Management of cloud and traditional environment is similar, apart from it done across the cloud customer and provider. Few aspects like security and privacy that create challenges in the cloud settings. Usage of electronic health record, field devices, internet of things and system maintenance are the aspects that demand supportive cloud environment. It is the responsibility of cloud customer to recognize the omitted SLO and notify the provider to take action and fulfill the demand on time.

\section{E. Hybrid Cloud Computing}

Combination of public and private cloud deployment model using multiple cloud services. By using it, connect on and off premises resources together. It plays essential role in integration, composition and organizational impact. It has different views for different people like solution designer, infrastructure and business team perspective.

1) Importance of hybrid cloud in healthcare

In technological era, to gear up the business needs and compete with the evolving applications that always demand agility and innovation in ideas. Key considerations of hybrid cloud in E-Health are:

- Decide the settlement of component

- Mix with prevailing enterprise system

- Handle the management complexity

- Make sure about the security in each aspect

- Deal with evolving technology

- Implementation of operational services

- Adherence to governing and agreement requirements

2) Effective implementation of hybrid cloud in e-health These steps that mentioned below ensure the execution of hybrid cloud from the viewpoint of cloud service customer.

- Define the appropriate deployment and cloud model for applications

- Incorporate with the current enterprise system

- Tackle connectivity demands

- Develop policies and service level agreement

- Access and determine the security and privacy challenges

- Cope with the hybrid cloud setting

- Consider backup and disaster recovery plan [21]

\section{F. Hybrid Cloud Computing Conceptual Framework for e-} health (see Fig. 3)

Healthcare provider has their own private cloud for data privacy because health record contains sensitive information about patient condition. Front-end is used to store data in private cloud of healthcare provider and share data with public cloud. That cloud is accessed by the other users as well. And at back-end public cloud have link with the private cloud that offering cloud applications services. Specific provide cloud getting services from another provider and having communication linkage with private cloud of healthcare provider. In this way the whole structure work and provide ehealth services to the healthcare organization for better performance and more productivity. 


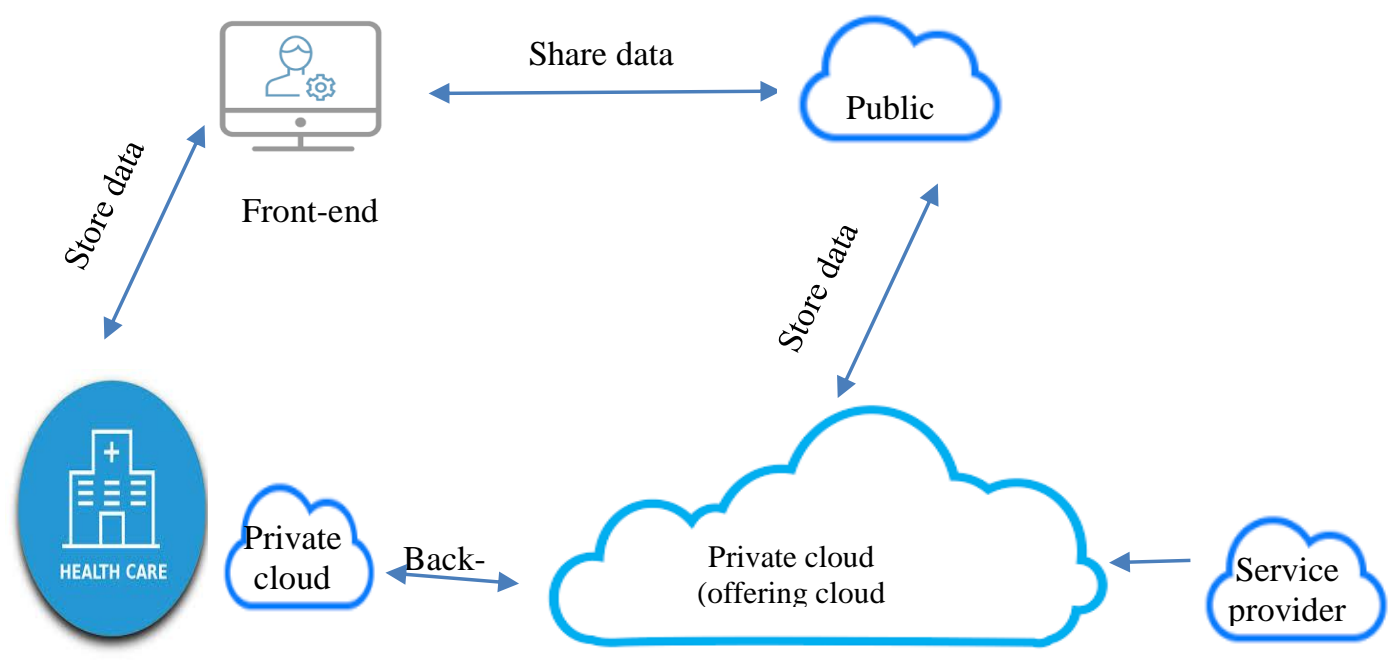

Fig. 3. Hybrid cloud computing conceptual framework for e-health.

\section{CONCLUSION}

In health sector, cloud computing technology enables the patient and doctors to access the information with ease. Important aspect of cloud is scalability that provide resources according to process requirements. Moreover it offers flexibility and cost reduction facility to organization. When healthcare organization move to cloud, first they must plan a strategy to keep in mind the existing resources. Above all it give opportunity to physicians and specialists to communicate with each other and share patient record across the globe. In healthcare cloud, security should be of utmost importance from the beginning. Privacy issues and maintenance are to be taken with care to create cloud service model or its deployment effective in the healthcare cloud applications. Adoption of cloud in health sector is also a technical aspect that demand proper information about the process. Provider and customer should have a detail understanding of the whole procedure. This paper describes the conceptual framework for smooth processing of health data by using hybrid cloud architecture.

\section{REFERENCES}

[1] Fox A. Cloud computing-what's in it for me as a scientist? Science 2011

[2] Doukas C, Pliakas T, Maglogiannis I. Mobile healthcare information management utilizing cloud computing and android OS. Conf Proc IEEE Eng Med Biol Soc 2010

[3] R. Zhang and L. Liu, "Security Models and Requirements for Healthcare Application Clouds", in Cloud Computing (CLOUD), 2010 IEEE 3rd International Conference on, Miami, FL, USA, USA, 2010, pp. 268-275.

[4] E. Mehraeen, H. Ayatollahi and M. Ahmadi, "Health Information Security in Hospitals: the Application of Security Safeguards", Acta Informatica Medica, vol. 24, no. 1, p. 47, 2016.

[5] O. Lupşe, M. Mihaela and L. Vida, "Cloud Computing and Interoperability in Healthcare Information Systems", pp. 81-85, 2012.

[6] M. Parekh and B. Saleena, "Designing a Cloud Based Framework for HealthCare System and Applying Clustering Techniques for Region Wise Diagnosis", Procedia Computer Science, vol. 50, pp. 537-542, 2015. http://dx.doi.org/10.1016/j.procs.2015.04.029

[7] W. Itani, A. Kayssi and A. Chehab, "Privacy as a Service: PrivacyAware Data Storage and Processing in Cloud Computing Architectures", in DASC '09. Eighth IEEE International Conference on, Chengdu, China, China, 2009, pp. 711-716.
[8] M. Alnuem, S. Youssef, A. Youssef and A. Emam, "Towards Integrating National Electronic Care Records in Saudi Arabia", in International Conference on Bioinformatics and Computational Biology, Monte Carlo Resort, Las Vegas, Nevada, USA, 2011.

[9] Mather T, Kumaraswamy S, Latif S. Cloud security and privacy. Beijing, Cambridge [Mass.]: O'Reilly, 2009.

[10] 10. Brunette G, Mogull R. Security guidance for critical areas of focus in cloud computing v2.1. http://www.cloudsecurityalliance.org [accessed 18 -Jan -2017].

[11] Priyanga.P, MuthuKumar.V.P "Cloud computing for healthcare organisation", International Journal of Multidisciplinary Research and Development, vol. 2, no. 4, pp. 487-493, 2015.

[12] "Global Healthcare Cloud Computing Market 2017-2021 | Technavio Discover Market Opportunities", Technavio.com, 2017. [Online]. Available: https://www.technavio.com/report/global-enterpriseapplication-global-healthcare-cloud-computing-market-2017-2021. [Accessed: 13- May- 2017].

[13] Cloud Standards Customer Council 2017, Impact of cloud computing on healthcare version $2.0 \mathrm{http} / / / \mathrm{www}$.cloud-council.org/deliverables/CSCCImpact-of-Cloud-Computing-on-Healthcare.pdf

[14] HIPAA http://www.hhs.gov/hipaa/

[15] Regulation (EU) 2016/679 of the European Parliament and of the Council (2016): EU General Data Protection Regulation. http://eurlex.europa.eu/legal-content/EN/TXT/?uri=CELEX:32016R0679

[16] Cloud Standards Customer Council 2015, Security for Cloud Computing: 10 Steps to Ensure Success, Version 2.0. http://www.cloudcouncil.org/deliverables/CSCC-Security-for-Cloud-Computing-10Steps-to-Ensure-Success.pdf

[17] NIST $\quad 800-160 \quad$ http://csrc.nist.gov/publications/drafts/800160/sp800_160_second-draft.pdf

[18] "Security Guidance: Cloud Security Alliance", Cloudsecurityalliance.org. [Online]. Available: https://cloudsecurityalliance.org/group/security-guidance/. [Accessed: 05- Feb- 2017].

[19] ISO/IEC 27017 (2015). Code of Practice for Information Security Controls Based on ISO/IEC 27002 for Cloud Services. http://www.iso.org/iso/catalogue_detail?csnumber $=43757$

[20] Cloud Standards Customer Council 2015, Practical Guide to Cloud Service Level Agreements, Version 2.0. http://www.cloudcouncil.org/deliverables/practical-guide-to-cloud-serviceagreements.htm

[21] Cloud Standards Customer Council 2016, Practical guide to hybrid cloud computing http://www.cloud-council.org/deliverables/CSCCPractical-Guide-to-Hybrid-Cloud-Computing.pdf 
[22] S. Miah, J. Hasan and J. Gammack, "On-Cloud Healthcare Clinic: An ehealth consultancy approach for remote communities in a developing country", Telematics and Informatics, vol. 34, no. 1, pp. 311-322, 2016.

[23] "DACAR Platform for eHealth Services Cloud", in IEEE International Conference on cloud computing, Washington, DC, USA, 2011, pp. 219226).

[24] N. Sultan, "Making use of cloud computing for healthcare provision: Opportunities and challenges", International Journal of Information Management, vol. 34, no. 2, pp. 177-184, 2014.

[25] 25. C. Lin, S. Abdul, D. Clinciu, J. Scholl, X. Jin, H. Lu, S. Chen, U. Iqbal, M. Heineck and Y. Li, "Empowering village doctors and enhancing rural healthcare using cloud computing in a rural area of mainland China", Computer Methods and Programs in Biomedicine, vol. 113, no. 2, pp. 585-592, 2014.

[26] A. Abbas and S. Khan, "A Review on the State-of-the-Art PrivacyPreserving Approaches in the e-Health Clouds", IEEE Journal of Biomedical and Health Informatics, vol. 18, no. 4, pp. 1431-1441, 2014.

[27] K. Sailunaz, M. Alhussein, M. Shahiduzzaman, F. Anowar and K. Mamun, "CMED: Cloud based medical system framework for rural health monitoring in developing countries", Computers \& Electrical Engineering, vol. 53, pp. 469-481, 2016.

[28] E. AbuKhousa, N. Mohamed and J. Al-Jaroodi, "e-Health Cloud: Opportunities and Challenges", Future Internet, vol. 4, no. 4, pp. 621645, 2012.

[29] G. Gavrilov and V. Trajkovik, "New model of Electronic Health Record: Macedonian case study", Journal of Emerging research and solutions in ICT, vol. 1, no. 2, pp. 86-99, 2016.

[30] R. Prasad Padhy, M. Ranjan Patra, and S. Chandra Satapathy, "Design and Implementation of a Cloud based Rural Healthcare Information System Model," vol. 2, no. 1, pp. 149-157, 2012.

[31] L. Devadass, S. Sekaran and R. Thinakaran, "CLOUD COMPUTING IN HEALTHCARE", International Journal of Students' Research in Technology \& Management, vol. 5, no. 1, p. 25, 2017.

[32] M. Joshi, "Proposed Cloud based Framework for Implementing EHealth Services in Uttarakhand", in International Conference on Advanced ComputingMukesh Joshi, 2016.

[33] N. Al Nuaimi, A. AlShamsi, N. Mohamed and J. Al-Jaroodi, "e-Health Cloud Implementation Issues and Efforts", in nternational Conference on Industrial Engineering and Operations Management, Dubai, United Arab Emirates (UAE), 2015.

[34] F. Els and L. Cilliers, "Improving the information security of personal electronic health records to protect a patient's health information", in Conference on Information Communications Technology and Society, 2017

[35] Pradeep Deshmukh, "Design of cloud security in the EHR for Indian healthcare services", 2016.

[36] Aziz H and Guled , "Cloud Computing and Healthcare Services", in 2016Journal of Biosensors \&Bioelectronics. DOI: 10.4172/21556210.1000220

[37] O. Boyinbode and G. Toriola, "CloudeMR: A Cloud Based Electronic Medical Record System", International Journal of Hybrid Information Technology, vol. 8, no. 4, pp. 201-212, 2015.

[38] B. Popovic and M. Maksimovic, "E-health in Bosnia and Herzegovina: exploring the challenges of widespread adoption".

[39] Sabanovic, Z., Masic, I., Salihefendic, N., Zildzic, M., Zunic, L. and Dedovic, S. (2009) E-Health in Bosnia - Starting from the Ground-Up, Acta Inform Med., 17(3): 135-138.

[40] Kadhum and M. Hasan, "Assessing the Determinants of Cloud Computing Services for Utilizing Health Information Systems: A Case Study", International Journal on Advanced Science, Engineering and Information Technology, vol. 7, no. 2, p. 503, 2017.
[41] D. Milenkovic, M. Jovanovic-Milenkovic, V. Vujin, A. Aleksic and Z. Radojicic, "Electronic health system: Development and implementation into the health system of the Republic of Serbia", Vojnosanitetski pregled, vol. 69, no. 10, pp. 880-890, 2012.

[42] R. Padhy, M. Patra and S. Satapathy, "Design and implementation of a cloud based rural healthcare information system model", 2012.

[43] Srivastava, P., Yadav, R and Razdan, P., Cloud Computing in Indian Healthcare Sector. Proceedings of ASCNT 2011, CDAC, Noida, India (2011)

[44] N. Karthikeyan and R. Sukanesh, "Case Study on Software as a Service (SaaS) Based Emergency Healthcare in India", European Journal of Scientific Research, vol. 69, no. 3, pp. 461-472, 2012.

[45] P. B, P. Rajasekaran.M and R. H.M, "WSN INTEGRATED CLOUD FOR AUTOMATED TELEMEDICINE (ATM) BASED $\mathrm{e}-$ HEALTHCARE APPLICATIONS", in 4th International Conference on Bioinformatics and Biomedical Technology, 2012.

[46] N. Botts, B. Thoms, A. Noamani and T. A. Horan, "Cloud Computing Architectures for the Underserved: Public Health Cyberinfrastructures through a Network of HealthATMs", in 43rd Hawaii International Conference on System Sciences, Honolulu, Hawaii, USA, USA, 2010.

[47] K. Tseng and C. Wu, "An Expert Fitness Diagnosis System Based on Elastic Cloud Computing", The Scientific World Journal, vol. 2014, pp. 1-10, 2014.

[48] C. Liu, F. Lin and D. Chiang, "Secure PHR Access Control Scheme for Healthcare Application Clouds", in 42nd International Conference on Parallel Processing, Lyon, France, 2013.

[49] A Hierarchical Framework for Secure and Scalable EHR Sharing and Access Control in Multi-cloud", in 41st International Conference on Parallel Processing Workshops, Pittsburgh, PA, USA, 2012.

[50] "Secure and Scalable Cloud-Based Architecture for e-Health Wireless Sensor Networks", in 21st International Conference on Computer Communications and Networks (ICCCN), Munich, Germany, 2012.

[51] Y. Tong, J. Sun, S. Chow and P. Li, "Towards auditable cloud-assisted access of encrypted health data", in IEEE Conference on Communications and Network Security (CNS), National Harbor, MD, USA, USA, 2013.

[52] L. Chen and D. Hoang, "Novel Data Protection Model in Healthcare Cloud", in IEEE International Conference on High Performance Computing and Communications, Banff, AB, Canada, 2011.

[53] M. Sharma, Y. Bai, S. Chung and L. Dai, "Using Risk in Access Control for Cloud-Assisted eHealth", in IEEE 14th International Conference on High Performance Computing and Communication \& 2012 IEEE 9th International Conference on Embedded Software and Systems, Liverpool, UK, 2012.

[54] H. Löhr, A. Sadeghi and M. Winandy, "Securing the E-Health Cloud", 2017.

[55] Z. Yu, C. Thomborson, C. Wang, J. Wang and R. Li, "A cloud-based watermarking method for health data security", in 35th Annual International Conference of the IEEE Engineering in Medicine and Biology Society (EMBC), Madrid, Spain, 2012.

[56] A. Alabdulatif and I. Khalil, "Protection of electronic health records (EHRs) in cloud Sign In or Purchase", in 35th Annual International Conference of the IEEE Engineering in Medicine and Biology Society (EMBC), Osaka, Japan, 2013.

[57] T. Ermakova and B. Fabian, "Secret Sharing for Health Data in Multiprovider Clouds", in IEEE 15th Conference on Business Informatics, Vienna, Austria, 2013. 